\section{Thermodynamic modelling of phase-chemical transformations as the method for study of rheological properties of substances}

AleXANDeR SLOBODOV - St. Petersburg State Institute of Technology, Physical Chemistry Department and ITMO University (St. Petersburg), Energetics Information Technology Department - aslobd@gmail.com

ANDREY USPENSKIY - ITMO University (St. Petersburg), Energetics Information Technology Department - andreyuspensky@rambler.ru

RICARDAS RALYS - ITMO University (St. Petersburg), Energetics Information Technology Department - ricardas.ralys@gmail.com

DMITRIY KREMNEV - St. Petersburg State Institute of Technology, Physical Chemistry Department - spbscout@narod.ru

Érkezett: 2015. 08. 15. - Received: 15. 08. 2015. - http://dx.doi.org/10.14382/epitoanyag-jsbcm.2015.27

\section{Abstract}

Theoretical methods for describing, modelling and calculation of phase-chemical transformations without limitations on numbers of components and phases has been developed with the aim of predicting, evaluating and optimizing the rheological properties of substances and materials, based on extreme thermodynamic functions principle (maximum entropy, minimum free energy, etc.). These methods and databases were implemented in the software-information complex ASTICS for thermodynamic simulation and calculation of phase-chemical transformations in multi-component engineering systems of different nature. The high effectiveness of the approach is illustrated by results obtained for various natural and engineering systems and processes mineral, rock, geochemical, silicate, glass, etc.

Keywords: rheology, thermodynamics, geochemistry, transformation, modelling, optimization, databases, multi-component system, mineral, silicate, glass

Kulcsszavak: reológia, termodinamika, geokémia, átalakulás, modellezés, optimalizálás, adatbázisok, többkomponensú rendszer, ásvány, szilikát, üveg

\section{Formulation of the problem}

The rheological properties of any substance and material depend not only on the composition and properties of its constituent components. These properties are determined, first of all, by the nature of chemical bonds between components, general characteristics and peculiarities of formation (composition) of the phase association, composing the substance (material) and conditions of these processes proceed. In other words, the rheology (structural-mechanical) properties of a substance are uniquely determined by its phasechemical state, peculiarities of its formation, the nature of the interparticle phase and chemical interactions in the bulk material, etc. [1,2].

Experimental investigation of simultaneous chemical and phase transformations is still too difficult in modern science and technology and therefore has incomplete solution. The major reason for high complexity of this problem underlies in multitude of simultaneous processes occurring in the wide range of temperatures and compositions. If one considers silicate systems, ceramics, glasses, firebreaks synthesis, it can be noticed that properties of final products are too different from those of the initial materials. These properties are resulted primarily from phase and chemical transformations, which proceed during the course of reaction.
Alexander SLOBODOV is Professor at St. Petersburg State Institute of Technology, Physical Chemistry Department and at ITMO University (St. Petersburg), Energetics Information Technology Department; Doctor of Science; Member of the New York Academy of Sciences; main fields of interest: thermodynamic physico-chemical research and modeling of multimathematics methods in physical chemistry, thermodynamic databases, material science.

Andrey USPENSKIY is a Post-graduate in Physical Chemistry at ITMO University (St. Petersburg), Energetics Information Technology Department; main fields of interest: Thermodynamic physico-chemical modeling of technological processes (polymers, silicates, glasses, etc.).

Ricardas RALYS is a Post-graduate in Physical Chemistry at ITMO University (St. Petersburg), Energetics Information Technology Department; main fields of interest: experimental thermal analysis, thermodynamic modeling and calculation of physico-chemical processes.

Dmitriy KREMNEV is a Post-graduate in Physical Chemistry at St Petersburg State Institute of Technology, Physical Chemistry Department; main fields of interest: thermodynamic physico-chemical modeling of inorganic systems (silicate, ceramics, etc.). component natural and technological systems,

In some cases, particularly in liquid and gaseous solutions, processes result in a complete transformation, meaning that such systems reach the equilibrium state. For such systems the justified and the most efficient way to investigate them is to use thermodynamic modelling, rather than conducting elaborate and expensive experiments to gather the information needed. In principle, thermodynamic modelling has the major advantage of being highly rigorous, and thus, more informative and detailed than direct experiments $[2,3]$.

It is specifically true if the investigators meet the following criteria when they take advantage of thermodynamic computations: use properties of substances involved in the reaction of interest of high reliability; and correctly interpret the results of modelling.

\section{Methodology}

\subsection{General idea}

Let us elaborate the method starting from basic ideas as general as possible. First, the system is considered consisting of $m$ basic or Gibbs components. It is assumed that these components form $n$ species because of all chemical reactions possible. The number of all species $n$ is not less than the number of components $m$. The difference $n-m$ is the number of dependent substances in all forms available, e.g., gases 
dissolved in liquid solutions, ions, precipitated solids, etc. The total quantity of components across all species in the reacting system always remains same independent of which transformations take place. This reflects natural constraint imposed on the system and is the so-called material balance condition.

The system is in equilibrium when a function characteristic to external conditions is in its global minimum point and satisfies the material balance constraint [4]. In case of constant pressure and temperature, the total Gibbs energy of the system is minimized in the following form:

$$
\left\{\begin{array}{l}
G=\sum_{i=1}^{n} \mu_{i} y_{i} \equiv \sum_{i=1}^{n}\left(\mu_{i}^{0}+R T \ln \gamma_{i} x_{i}\right) y_{i} \rightarrow \min _{\left\{y_{i}\right\}} \\
\sum_{i=1}^{n} a_{i j} y_{i}=y_{j}^{0}, \quad j \in 1: m \\
y_{i} \geq 0, \quad i \in 1: n
\end{array}\right.
$$

where $y_{i}^{0}$ is the number of moles of basic components of the system; $a_{i j}$ is the stoichiometric matrix of the system; $y_{i}$ is the number of moles of all species in equilibrated system; $\mu_{i}$ is the chemical potential of the species $i, \mu_{i}^{0}$ is the standard chemical potential of the species $i ; x_{i}$ is the molar fraction of the species $i ; \gamma_{i}$ is the coefficient of activity of the species $i$.

Coefficients of activity depend on the model of excessive functions describing non-ideality of the system. In systems with pure substances, one should consider ideal conditions and, thus, phase transitions.

The problem described in a system given by Eq. (1) consists of three major parts:

1. Condition of minimum of the function of $n$ variables the total Gibbs energy;

2. Condition of basic components preservation;

3. Condition of non-negativity of the quantity of any species presented in the system.

One shall notice that the system given by Eq. (1) is not a model of equilibrium. It is a rigorous description of any real system in equilibrium. Any uncertainty associated with the solution of a problem given by Eq. (1) arises only from uncertainties of excessive function models and/or incomplete standard thermodynamic properties. The need to assess missing or unreliable data causes the need to model these data, which is only an auxiliary task, and the formulation of Eq. (1) still remains certain, however.

In this way, the level of reliability of the modelling results - the main investigation quality criterion - is defined via the level of problem description reliability, the quality of raw data, and the efficiency of the solution to the problem given by Eq. (1).

It is also worth noting, that Eq. (1) is only one from the set of possible formulations. Different objective functions can be used depending on what the external conditions are. For example, constant overall composition $y^{0}$, volume $V$, and entropy $S$ correspond to internal energy $U$; constant overall composition $y^{0}$, temperature $T$, and volume $V$ correspond to
Helmholtz free energy $A$; constant overall composition $y^{0}$, temperature $T$, and pressure $P$ correspond to Gibbs energy $G$.

One can use Lagrange function instead of characteristic function, when seeking for equilibrium solution. For example, for internal energy $U$ the problem given by Eq. (1) transforms into the following expression:

$$
\begin{aligned}
& \left(L\left\{V^{(k)}, S^{(k)}, y_{1}^{(k)}, \ldots, y_{n}^{(k)}\right\}, \lambda_{V}, \lambda_{S},\left\{\lambda_{j}\right\}\right)=U\left(\left\{V^{(k)}, S^{(k)}, y_{1}^{(k)}, \ldots, y_{n}^{(k)}\right\}_{k=1}^{r}\right)+ \\
& +\lambda_{V}\left(-V^{0}+\sum_{k=1}^{r} V^{(k)}\right)+\lambda_{S}\left(-S^{0}+\sum_{k=1}^{r} S^{(k)}\right)+\sum_{j=1}^{m} \lambda_{j}\left(-y_{j}^{0}+\sum_{k=1}^{r} \sum_{i=1}^{m} a_{i j} y_{i}^{(k)}\right) \rightarrow \min
\end{aligned}
$$

Problem in the form of Eq. (2) excludes the need to consider material balance and external constraints, only the "natural requirement" of substances quantities non-negativity remains. If only this "natural requirement" remains as the constraint, then the original problem is divided into the two separate tasks: the first one is the "core" task related to only internal state variables, which are species and phase composition. This "core" problem may be written as follows:

$$
\begin{aligned}
& \mu_{i}^{(k)}=\sum_{j=1}^{m} a_{i j} \mu_{j}, \quad(i, k) \in I^{0}: y_{i}^{(k)}>0 \\
& \mu_{i}^{(k)} \geq \sum_{j=1}^{m} a_{i j} \mu_{j}, \quad(i, k) \notin I^{0}: y_{i}^{(k)}=0 \\
& \sum_{k=1}^{r}\left(\sum_{i=1}^{n} a_{i j} y_{i}^{(k)}\right)=y_{i}^{0}, \quad j \in 1: m
\end{aligned}
$$

where $\{y, \ldots, y\}, k=1 . . r)$ is the composition of $k$-th phase, $r$ is the number of phases, $n$ is the number of chemical species in the system which are defined by stoichiometric matrix $\left\{a_{i j}\right\}$ and basic components with number of $m$.

\subsection{Practical challenges}

One shall notice that in the most practical cases minimization problem may be reduced to a much simpler one. In fact, most of the time, in real systems one observes either chemical transformation, or phase transition.

Problems involving only phase transitions require just to find set of phases, whilst chemical reactions are simple (or even non-existent). Such processes may be readily observed when dealing with natural geological or geophysical phenomena, or when processing materials in industry. For such systems, it is needed to find phase composition, and chemical equilibrium solution often turns to be trivial or even not requiring any actions at all.

Problems related to chemical transformations with the $a$ priory known phases and their compositions do not need complicated solutions, too. For such systems it is just needed to find quantitative composition of each phase without the need to involve virtual species from non-existing phases.

The conditions given by Eqs. (1)-(3) reflect the material balance, and Lagrange function $L$ minimum which is the generalized law of reacting masses. It is shown that specific constraints posed to the system, such as $\mathrm{P}, \mathrm{V}$, or $\mathrm{S}$, are readily taken into account without loss of method generality described by Eqs. (1)-(3). 
When seeking for the solution, one can divide the iterative solving into two sub-tasks: "phase" sub-task, and "chemical" sub-task. In the "phase" sub-task one can find the qualitative phase composition $\mathrm{I}^{0}$, i.e. which compounds actually form the phase. In the "chemical" sub-task implementation one can find the quantitative phase composition, which means in quantities the found compounds are present in the phase. Convergence criterion showing in which direction we need to move is the direction of $L$ function descent. Sub-routines solving each subtask and the whole problem could be formulated as well.

Despite the fact that one deals with problems either only of the first type, or only of the second type in most cases, it is evident that one may face much more complex processes in some cases, which involve both chemical transformations and phase transitions. Attempt to solve such problems takes lots of tedious calculations and high quality input data. Up to the date existing packages and software applications allow to solve only either of the problems, and, thus, it is a great and unsatisfied demand to solve simultaneous phase-chemical equilibrium problems.

\section{Results and Discussion}

\subsection{Thermodynamic modelling procedure}

During the solution of the problem either in the form of Eq. (1) or in the form of Eqs. (2)-(5), the need to find roots to non-linear equations always emerges. In fact, a closed form solution cannot be found to such equations, and, thus, iterative methods are needed to be involved.

Most of the iterative methods require in their turn to find the convergence region and to find the path with the highest convergence rate possible. In addition, specific requirements should be incorporated arising from the chemical nature of the system of interest.

Analysis of available literature [1-6] shows that both of the convergence problems are far from a good solution, despite the variety of methods being offered to date.

Before proceeding to the essence of the solution presented in this work, it must be noted that the problem is naturally divided into two interrelated parts: "qualitative" part and "quantitative" part. These parts are distinguished by the different role, which plays the equilibrium phase composition $\mathrm{I}^{0}$.

When dealing with "qualitative" problem, one should seek for the phase composition. This means that all possible phases are needed to be found that are in equilibrium. After this task is accomplished, one should move to the "qualitative" problem. In this stage, the calculation of quantitative composition of each phase in equilibrium is needed.

Therefore, bearing in mind these two interrelated tasks, the following strategy has been developed in seeking the simultaneous phase-chemical equilibrium solution. It starts from the initial point corresponding to the feed composition. Species with zero quantities are excluded from consideration and turn the non-equalities of Eqs. (3)-(5) into the following equations:

$$
\mu_{i}^{(k)}=\sum_{j=1}^{m} a_{i j} \mu_{j}, \quad(i, k) \in I_{t}^{0}
$$

$\sum_{(i, k) \in I_{t}^{0}} a_{i j} y_{i}^{(k)}=y_{j}^{0}, \quad j \in 1: m$

Then the problem given by Eqs. (6) and (7) is solved only for components with non-zero concentration (in the phases in interest). After finding that solution, it should be checked against the non-equalities given by Eqs. (3) and (4):

$y_{i}^{(k)}>0, \quad(i, k) \in I_{t}^{0}$

$\mu_{i}^{(k)} \geq \sum_{j=1}^{m} a_{i j} \mu_{j}, \quad(i, k) \notin I_{t}^{0}$

If the solution meets these non-equalities, the computation is halted and the last results are stated as the result that satisfies the equilibrium condition. If the inequalities given by Eqs. (8) and (9) are not satisfied, then the "quantitative" phase composition is recalculated. When doing so, it should be considered which phases are needed to be included to the first task solution, and which phases have to be dismissed. After the new phase composition is evaluated, the calculation is continued with the second "quantitative" task until the solution converges to all inequalities given by Eqs. (8) and (9) being satisfied.

Modern state of optimization methods are of the great avail when applying them to the above-described two steps iteration procedure.

Despite high thermodynamic and mathematical rigor of the proposed methodology, we still may face pitfalls. Those pitfalls are mainly attributed to the quality of thermodynamic data available in the literature. The following requirements are need to be addressed to overcome data quality issues: the data should be complete in regard of which substances are available; thermodynamic properties accompanying the substances should allow the complete description of those; the data on properties should be of high reliability.

When considering the requirements, the necessary and sufficient properties that allow describing the system of inters must be defined in order to get accurate result.

To do so, the transformed equation of the Gibbs energy is considered as follows:

$$
\begin{aligned}
& \widetilde{G}^{0}(P, T)=\Delta_{f} G^{0}\left(P_{0}, T_{0}\right)-S^{0}\left(P_{0}, T_{0}\right)\left(T-T_{0}\right)+ \\
+ & \sum_{j=1}^{k}\left[\begin{array}{c}
T_{j} \\
T_{T_{j-1}}
\end{array} C_{j}^{0}\left(P_{0}, t\right) d t-\int_{T_{j-1}}^{T_{j}} C_{j}^{0}\left(P_{0}, t\right) d t+\left(\begin{array}{l}
T \\
T_{j}
\end{array}-1\right) \Delta H_{j}^{0}\left(P_{0}, T_{j}\right)\right]+\int_{P_{0}}^{P} V^{0}(p, T) d p
\end{aligned}
$$

It may be noticed that the requirements stated above are still not satisfied when taking a close look at the data on thermodynamic properties available in the literature [7-11]. This brings in another issue to solve. Testing of thermodynamic properties data against self-consistency, and finding the way to calculate correctly the missing data is needed.

Applying the strategy described above systematically, the set of high quality data for numerous substances have been created. These data are stored in the ASTIB database. Together with the package to solve phase-chemical equilibriums (ASCAT) based on the procedure that has been described earlier, this database forms the ASTICS application. 


\subsection{Application of the developed methods}

A few real life cases are described in the followings in order to illustrate possibilities of the methodology offered in this work.

In Fig. 1 it can be seen how temperature influences the ceramics synthesis process in a silicate system - made of fourteen elements. Phase and phase-chemical transitions shown in Fig. 1 give the answers on which phases and in which quantities are formed, how their composition depends on gas composition and properties, which gaseous products are evolving during the synthesis.

$$
\mathrm{SiO}_{2}-\mathrm{K}_{2} \mathrm{O}-\mathrm{Na}_{2} \mathrm{O}-\mathrm{Al}_{2} \mathrm{O}_{3}-\mathrm{Fe}_{2} \mathrm{O}_{3}-\mathrm{CaO}-\mathrm{MgO}-\mathrm{TiO}_{2}-\mathrm{P}_{2} \mathrm{O}_{5}-\mathrm{SO}_{3}, \mathrm{~V}=10^{-4} \mathrm{M} / \mathrm{kT}
$$

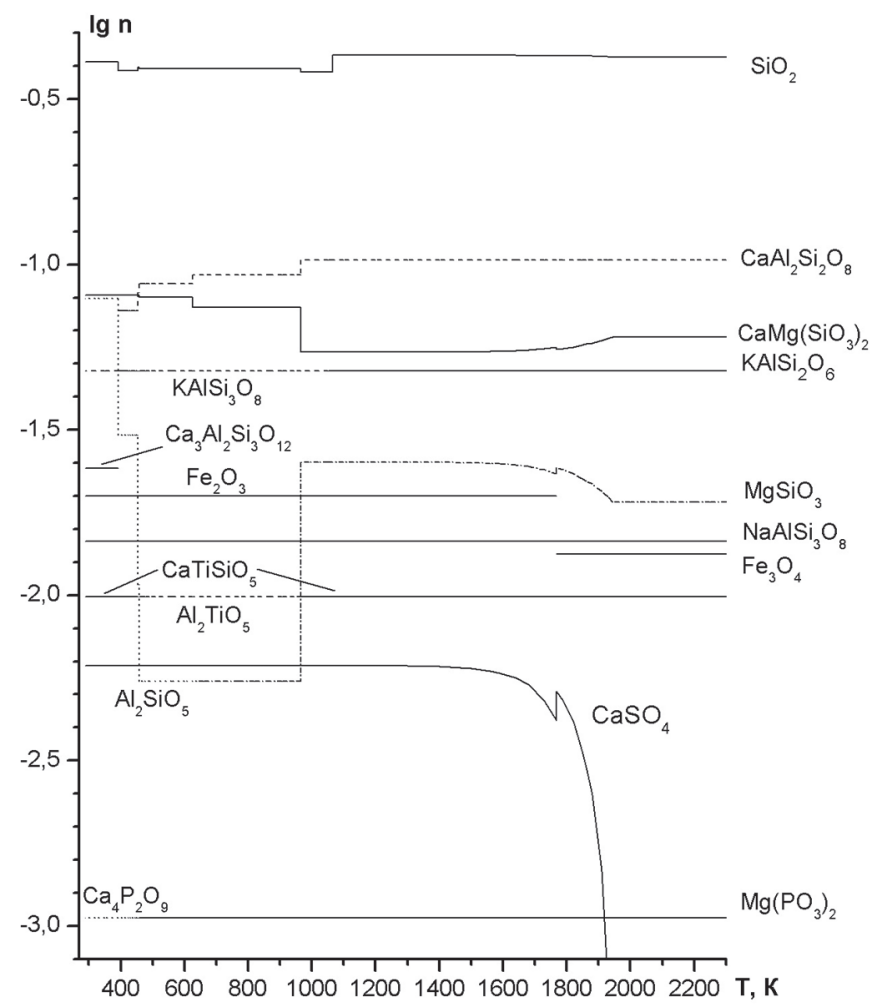

Fig. 1. Modelling and computation results in silicate system - influence of temperature on phase and chemical transformations for ceramics synthesis

1. ábra Szilikát rendszer modellezése - a hőmérséklet hatása a fázisokra és a kémiai átalakulásokra kerámia szintézis során

In Fig. 2 the result of modelling another important system is presented. The process of cleansing an atomic power station from corrosion products is shown. It can be readily seen, how the phases are transformed, which complexes are present in the aqueous solution, how $\mathrm{pH}$ value changes across the temperature range. This modelling gives the result on the overall solubility, which is in the excellent agreement with practically observed values.

As a result of these thermodynamic models and phasechemical compositions, not only rheological properties of the materials can be explained but optimization of technological conditions of their synthesis (temperature regime, initial composition) is also possible.

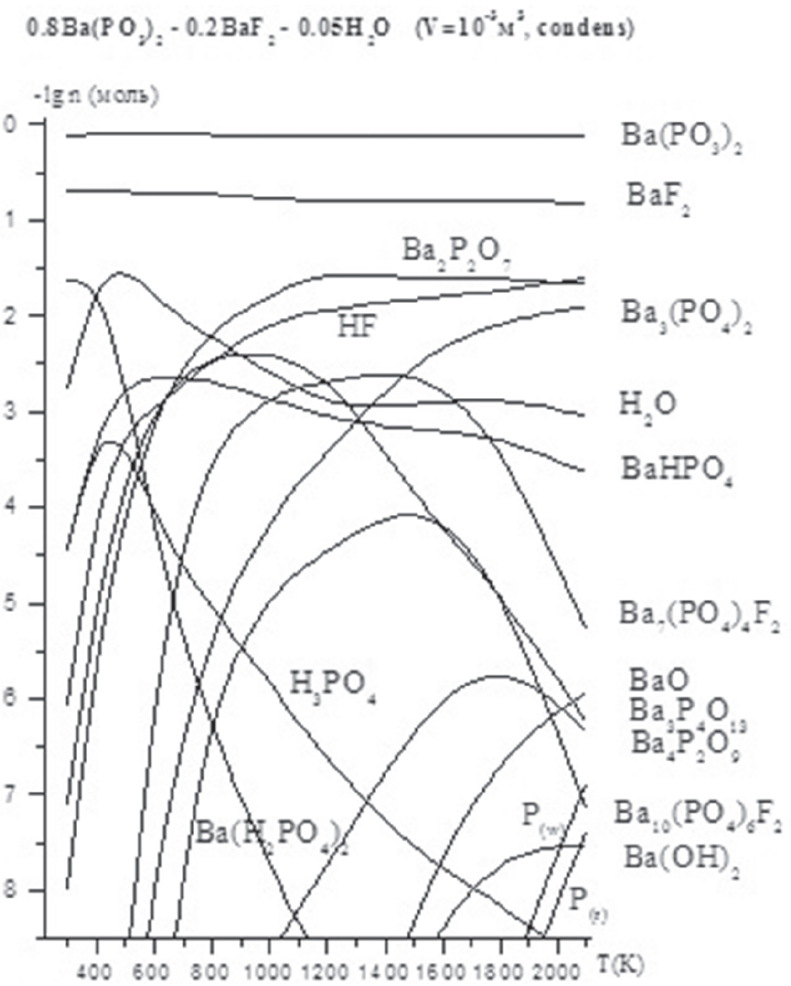

Fig. 2. Modelling and computation results for the phosphate-fluoride barium glasses synthesis - influence of temperature on physicochemical transformations

2. ábra Foszfát-fluorid-bárium üveg szintézis modellezése - a hömérséklet hatása a fiziko-kémiai átalakulásokra

\section{Conclusions}

In the presented work, the general formulation on how to solve simultaneous phase-chemical equilibrium problems with use of strict and rigorous thermodynamic evaluations (without limitations on numbers of components and phases) has been shown. Based on these evaluations, a package has been developed to treat data on initial system composition in order to get equilibrium composition.

This treatment also uses database with revised, consistent, and reliable data on thermodynamic properties of numerous substances. The application including both the database and computation routines, allowed us to model and optimize the variety of systems, and to gather rich information on mechanisms of processes occurring in these systems [12-14]. Evaluated data was demonstrated to be in excellent agreement with experimentally observed data.

The data obtained by modelling and computation with the help of the developed software, showed not only good coherence with well known experimental data (which in most cases tend to be scarce and incomplete), but also provided more qualitative and quantitative information about mechanisms of processes taking place in the systems of interest, rheological properties, opportunities of natural and technological process optimization.

\section{References}

[1] Smith, W. R. (1980): Computational aspects of chemical equilibrium in complex systems. Theoretical Chemistry: Advances and Perspectives, Academic Press, pp. 185-259. 
[2] Slobodov, A. A. - Kritskii, V. G. - Zarembo, V. I. - Puchkov, L. V. (1988): Solubility products of steel corrosion in conditions simulating water chemistry reactors. Russian Journal of Applied Chemistry. Vol. 61, No. 10. pp. 2661-2667.

[3] Suvorov, S. A. - Slobodov, A. A. - Bocharov, S. V. - Borzov, D. N. Matuzenko, M. Yu. (2003): Thermodynamic simulation of the behavior of a carbonized refractory. Refractories and Industrial Ceramics. Vol. 44, No. 2, pp. 84-88. http://dx.doi.org/10.1023/A:1024706909341

[4] Gibbs, J. W. (1928): The collected works. Thermodynamics: Vol. 1, Longmans, Green and Co., $434 \mathrm{p}$.

[5] Vasilenko, G. V. - Zarembo, V. I. - Slobodov, A. A. - Dooley, R. B. (1995): Relationship between the distribution coefficients of boiler water impurities and dissociation constants. Thermal Engineering. No. 7, p.64.

[6] Ball, J. W. - Nordstrom, D. K. (1991): User's manual for WATEQ4F with revised thermodynamic data base and test cases for calculating speciation of major, trace and redox elements in natural waters. U.S. Geological Survey, $189 \mathrm{p}$.

[7] Smith, R. M. - Martell, A. E. (1976): Critical stability constants. Plenum Press, $256 \mathrm{p}$.

[8] Wagman, D. D. - Evans, W. H. - Parker, V. B. - Schumm, V. B. - Halow, I. - Bailey, S. M. - Churney, K. L. - Nuttall, R. L. (1982): The NBS table of chemical thermodynamic properties. Selected values for inorganic and $\mathrm{C} 1$ and C2 organic substances in SI units. J. Phys. Chem. Ref. Data. V.11, Suppl. 2. -394 p.

[9] Chase, M. W. (Ed.) (1998): NIST-JANAF Thermochemical Tables: Part I, II. (4 ${ }^{\text {th }}$ Ed.), Journal of Physical and Chemical Reference Data, Monograph No. 9, NSRDS-AChS-AIPh, $1151 \mathrm{p}$.
[10] Glushko, V. P. (Ed.) (1981): Thermal Constants of Substances: Guide, Vol. 1-10. USSR Academy of Sciences

[11] Mohr, P. J. - Taylor, B. N. - Newell, D. B. (2007): CODATA Recommended Values of the Fundamental Physical Constants: 2006. NIST, 105 p.

[12] Kritskii, V. G. - Slobodov, A. A. (2009): Predicting Growth of Deposits on Fuel Assemblies of VVER-440 Reactors. Thermal Engineering, Vol. 56, No. 5, pp. 387-389. http://dx.doi.org/10.1134/S004060150905005X

[13] Veiko, V. P. - Slobodov, A. A. - Odintsova, G. V. (2013): Availability of Methods of Chemical Thermodynamics and Kinetics for the Analysis of Chemical Transformations on Metal Surfaces under Pulsed Laser Action. Laser Physics, Vol. 23. No. 6, p. 066001. http://dx.doi.org/10.1088/1054-660X/23/6/066001

[14] Slobodov, A. A. - Uspenskiy, A. B. - Kuznetsova, Z. G. - Shinkarenko, A. V. (2015): The Efficiency Problem of Thermodynamic Modeling and Calculation of Phase-Chemical Transformations in Multicomponent Systems. 13th Joint European Thermodynamics Conference, JETC-2015, Book of Abstracts. ENSIC Nancy - May 20-22, 2015. pp. 183-184.

$\underline{\text { Ref.: }}$

Slobodov, Alexander - Uspenskiy, Andrey - Ralys, Ricardas Kremnev, Dmitriy: Thermodynamic modelling of phase-chemical transformations as the method for study of rheological properties of substances

Építöanyag - Journal of Silicate Based and Composite Materials, Vol. 67, No. 4 (2015), 159-163. p.

http://dx.doi.org/10.14382/epitoanyag-jsbcm.2015.27

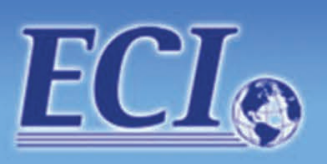

International Workshop on the Environmental Damage in Structural Materials Under Static Load/Cyclic Loads at Ambient Temperatures An $\mathrm{ECl}$ Conference Series May 29-June 3, 2016 • The Imperial Hotel, Cork, Ireland

Overview: Environmentally-assisted cracking, EAC, of engineering materials has been known for at least 50 years. The sensitivity of engineering alloys to environmental exposure is well known from an engineering perspective. What is not known with certainty at this stage is the mechanism by which the many manifestations of EAC occur. This understanding is fundamental to the development of strategies for control and predict failures of EAC is of great importance to the failure communities.

While significant progress in our understanding of EAC has been achieved in recent years, important fundamental questions like "how environment affects the crack driving force", and "why do ordinarily ductile materials fail in a brittle manner when exposed to certain environments" remain unanswered.

Our objective is to congregate a group of "skilled in the field" researchers in metallic materials for a workshop style conference that will endeavor to help clarify our current understanding of EAC and identify approaches to improve the current semi-quantitative understanding of the mechanisms.

\section{The emphasis of the presentations will be on:}

- Systematic evaluation of the governing parameters such as thresholds stress intensity factors, crack growth rates, steady state behavior, effects of yield stress, microstructure, and concentration of the aggressive environment (aqueous, gaseous, LME), and load-history on static/cyclic corrosion crack growth;

- Papers including experimental data for crack initiation and/or growth and those exploring unifying principles governing these time-static/cyclic stress dependent crack growth phenomena are particularly welcome;

- Analysis of crack tip microscopy, chemistry;

- New techniques for measuring crack initiation in aqueous environment;

- Emphasis is on understanding and quantifying rather than reporting the data of some material response;

- All topics are to be at room temperature; no high temperature work is accepted

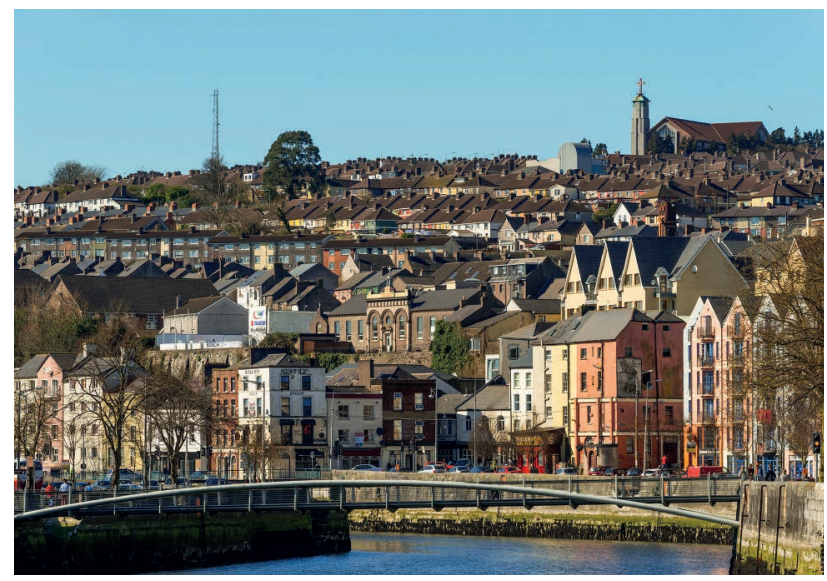

Scope

The scope of symposium includes the fundamental understanding of EAC from the initiation stage to growth and final failure in engineering alloys.

\section{Preliminary Technical Topics:}

- Systematic variation of threshold KIscc and steady state (da/dt) in aqueous and gaseous environments

- Role of internal/external hydrogen on threshold $\mathrm{K}$ and crack growth

- Crack tip chemistry and microscopy

- Modeling of the governing mechanisms-atomistic and continuum

http://www.engconf.org/conferences/civil-and-environmental-engineering/international-workshop-on-the-environmental-damage-in-structuralmaterials-under-static-Ioadcyclic-loads-at-ambient-temperatures/ 